\title{
Rheological properties of ultraviolet-irradiated and thermally pasteurized Yankee pineapple juice
}

\begin{abstract}
The rheological behaviour of Yankee pineapple juice was examined for the effect of ultraviolet (UV) irradiation $(53.42 \mathrm{~mJ} / \mathrm{cm} 2)$ and compared with untreated juice and a thermally pasteurized $\left(80{ }^{\circ} \mathrm{C}\right.$ for $\left.10 \mathrm{~min}\right)$ juice. A rheological test was performed on all types of juice in the temperature range $5{ }^{\circ} \mathrm{C}$ to $25{ }^{\circ} \mathrm{C}$ using a concentric cylinder rheometer at a shear rate range of 10-290 s-1. The comparative analysis found that the best flow curves were described by the Bingham model with an initial shear stress. The entangled pulps in the juices prevented free flow at zero shear rate. There was no significant variation between the plastic viscosities of the untreated and UV-irradiated juice at all temperatures. The activation energy $(\mathrm{Ea})$ of the untreated, UV-irradiated and thermally pasteurized juice was $6.80,8.19$ and $8.50 \mathrm{~kJ} / \mathrm{mol}$ respectively.
\end{abstract}

Keyword: Pineapple; Pasteurization; Juice; Viscosity; Arrhenius 